in vivo $33: 1151-1156(2019)$

doi:10.21873/invivo.11585

\title{
Association of Caspase-8 Genotypes With Oral Cancer Risk in Taiwan
}

\author{
LIANG-CHUN SHIH ${ }^{1,2,3^{*}}$, CHIA-WEN TSAI ${ }^{3 *}$, KUO-TING SUN ${ }^{3 *}$, \\ HUAI-MEI HSU ${ }^{3}$, TE-CHUN SHEN ${ }^{3}$, YUEH-TING TSAI ${ }^{3}$, WEN-SHIN CHANG ${ }^{3}$, \\ MENG-LIANG LIN ${ }^{4}$, YUN-CHI WANG ${ }^{3}$, CHI-LI GONG ${ }^{5}$ and DA-TIAN BAU ${ }^{1,3,6}$ \\ ${ }^{1}$ Graduate Institute of Biomedical Sciences, China Medical University, Taichung, Taiwan, R.O.C.; \\ ${ }^{2}$ Department of Otolaryngology, China Medical University Hospital, Taichung, Taiwan, R.O.C.; \\ ${ }^{3}$ Terry Fox Cancer Research Laboratory, Translational Medicine Research Center, \\ China Medical University Hospital, Taichung, Taiwan, R.O.C.; \\ ${ }^{4}$ Department of Medical Laboratory Science and Biotechnology, \\ China Medical University, Taichung, Taiwan, R.O.C.; \\ ${ }^{5}$ Department of Physiology, China Medical University, Taichung, Taiwan, R.O.C.; \\ ${ }^{6}$ Department of Bioinformatics and Medical Engineering, Asia University, Taichung, Taiwan, R.O.C.
}

\begin{abstract}
Background/Aim: Recently, mounting evidence has shown that caspase-8 (CASP8) rs3834129 (-652, 6N insertion/deletion) polymorphism may serve as a genetic biomarker for personal risk of various cancer types. The contribution of CASP8 rs3834129 polymorphism has been investigated in several oral cancer populations, but not in Taiwan. This study investigated the role of CASP8 rs3834129 polymorphism on oral risk in Taiwan. Materials and Methods: CASP8 rs3834129 polymorphic genotypes were determined and their associations with oral cancer risk were investigated among 788 patients with oral cancer and 956 age-and gender-matched healthy controls via polymerase chain reaction-restrictive fragment length polymorphism (PCR-RFLP) methodology. In addition, the interaction of CASP8 rs3834129 genotype with personal behavior and clinicopathological features were also examined. Results: The frequencies of II, ID and DD genotypes for CASP8 rs3834129 were 57.5, 36.5 and $6.0 \%$ in the patient group and 54.0, 39.0 and $7.0 \%$ in the healthy control group,
\end{abstract}

This article is freely accessible online.

*These Authors contributed equally to this study.

Correspondence to: Da-Tian Bau and Chi-Li Gong, Terry Fox Cancer Research Laboratory, Translational Medicine Research Center, China Medical University Hospital, 2 Yuh-Der Road, Taichung, 404 Taiwan, ROC. Tel: +886 422053366 (Ext. 5805), e-mail: datian@mail.cmuh.org.tw; artbau2@gmail.com

Key Words: Case-control study, caspase-8, oral cancer, genotype, polymorphism, Taiwan. respectively ( $p$ for trend=0.3052), genotypes were not significantly differentially distributed between the two groups. The comparisons in allelic frequency distribution also supported the findings that the $D$ variant allele may not serve as a determinant of risk for oral cancer. There was no interaction of CASP8 rs3834129 genotype with age, gender, smoking, alcohol or betel quid consumption in regard to oral cancer risk. Conclusion: Our results indicate that the caspase-8 genotype does not appear to play a direct role in personal susceptibility to oral cancer in Taiwan.

Oral cancer is the eighth most commonly diagnosed cancer among men in the world, and about twice more prevalent than among women in the world (1). In Taiwan, the incidence and mortality of oral cancer has occupied the fourth and fifth places among the common cancer types for many years (2), and its high incidence has been proposed to be closely associated with the combinative effects of smoking, alcoholism and, betel quid chewing in addition to genetic factors (3-6). However, the definitive genomic etiology of oral cancer remains largely unknown. In Taiwan, although several useful biomarkers for early detection of oral cancer have been revealed (7-13), the mechanisms underlying them are largely unknown and practical genomic markers for clinical use are still in urgent need. Noticeably, Taiwan has over of the highest densities worldwide of patients with oral cancer.

Apoptosis is a bio-essential mechanism for altering the morphology, and controlling the death rate of a stable population (14). In the literature, mounting evidence has shown loss of homeostasis of the apoptosis pathway to be associated with the development of oral cancer (15), and 
genomic polymorphisms of caspase-8 (CASP8), one of the most important components of this family of proteins in extrinsic apoptosis signaling $(16,17)$, may serve as a biomarker for oral cancer.

Among the polymorphic sites of CASP8, rs3834129 (-652, $6 \mathrm{~N}$ ins/del) polymorphism, a six-nucleotide insertion (I)/deletion (D) variant, has been functionally identified to lead to down-regulation of the mRNA of CASP8 (18). Caspase- 8 single nucleotide polymorphisms are reported to be genomic markers for the prediction of the personal risk for several types of cancers such as that of the digestive tract $(19,20)$, breast (21-23), prostate (24), lung (25) and bladder (26), and neuroblastoma (27). Little is known about the role of CASP8 polymorphisms in oral cancer.

In 2017, one epidemiological study on a South Indian oral cancer population reported no association between CASP8 rs3834129 polymorphism and oral cancer risk (28), a finding which has not yet been validated in other populations. Thus, in the current study, we aimed to determine the genotype of CASP8 rs3834129 polymorphism, evaluate its association with oral cancer risk, and examine the joint effects of CASP8 rs3834129 genotype with lifestyle factors in a representative Taiwanese population.

\section{Materials and Methods}

Collected population. The protocols in collecting participants for the current study were approved by the Institutional Review Board of the China Medical University Hospital (DMR101-IRB1-306), while written-informed consent was obtained from all the participants. In total, 788 patients diagnosed with oral cancer were recruited in this study. All participants voluntarily joined, fully understood the purpose and aims of the study, willingly completed a self-administered questionnaire and provided $5 \mathrm{ml}$ of their peripheral blood. The questionnaire contents helped the translational scientists to fully understand the cancer history and frequency of alcohol consumption, areca chewing and smoking habits of the participants. The alcohol consumption, areca chewing and smoking habits for each participant were evaluated and classified as categorical variables. Information on these personal behaviors were further evaluated by defining that occurring more than twice a week for years as 'ever'. A total of 956 non-cancer healthy individuals were selected by matching for age and gender after initial random sampling from the Health Examination Cohort of the hospital, and excluding those with any history of cancer themselves or for their first-order relatives. The male versus female ratio was $76 \%$ to $24 \%$ in the case and control groups, while the average ages of the case and control groups were $55.8(\mathrm{SD}=9.9)$ and $56.6(\mathrm{SD}=8.7)$ years, respectively. The information of selected characteristics for all the participants is concisely summarized in Table I.

Genotyping conditions for CASP8 rs3834129. The genomic DNA for each participant was extracted from their peripheral blood leukocytes with the QIAamp Blood Mini Kit (Blossom, Taipei, Taiwan, ROC), and stored long-term at $-80^{\circ} \mathrm{C}$, subsequently $100-$ fold diluted and aliquoted for genotyping as a working stock at $-20^{\circ} \mathrm{C}$ as previously published $(6,29)$. The genotyping methodology
Table I. Selected characteristics of the 788 patients with oral cancer and 956 controls.

\begin{tabular}{lccc}
\hline Characteristic & $\begin{array}{c}\text { Controls } \\
(\mathrm{n}=956)\end{array}$ & $\begin{array}{c}\text { Cases } \\
(\mathrm{n}=788)\end{array}$ & $p$-Value \\
\hline Age (years) & $56.6 \pm 8.7$ & $55.8 \pm 9.9$ & \multicolumn{1}{c}{$0.7951^{\mathrm{a}}$} \\
Gender, n (\%) & $727(76.0 \%)$ & $599(76.0 \%)$ & \\
$\quad$ Male & $229(24.0 \%)$ & $189(24.0 \%)$ & \\
Female & & & \\
Personal habit, $\mathrm{n}(\%)$ & $667(69.8 \%)$ & $595(75.5 \%)$ & $\mathbf{0 . 0 0 8 4}^{\mathrm{b}}$ \\
Cigarette smoking & $641(67.1 \%)$ & $560(71.1 \%)$ & $0.0773^{\mathrm{b}}$ \\
Alcohol drinking & $506(52.9 \%)$ & $661(83.9 \%)$ & $<\mathbf{0 . 0 0 0 1}$ \\
Betel quid chewing & & $325(41.2 \%)$ & \\
Primary tumor site, $\mathrm{n}(\%)$ & & $294(37.3 \%)$ & \\
Tongue & & $303.8 \%)$ & \\
Buccal mucosa & & $263.3 \%)$ & \\
Mouth floor & & $182.3 \%)$ & \\
Retromolar trigone & & $182.3 \%)$ & \\
Alveolar ridge & & $394.9 \%)$ & \\
Palate & & $384.9 \%)$ & \\
Lip & & & \\
Other & & &
\end{tabular}

SD: Standard deviation; aBased on Student's $t$-test; bBased on chisquare test. Significant $p$-values $(p<0.05)$ are shown in bold.

for CASP8 rs3834129 regarding the designing of the primer pairs and the selection of restriction enzyme were as follows. In brief, the polymerase chain reaction (PCR) cycling conditions were: one cycle at $94^{\circ} \mathrm{C}$ for $5 \mathrm{~min} ; 35$ cycles of $94^{\circ} \mathrm{C}$ for $30 \mathrm{~s} ; 59^{\circ} \mathrm{C}$ for $30 \mathrm{~s}$ and $72^{\circ} \mathrm{C}$ for $30 \mathrm{~s}$; with a final extension at $72^{\circ} \mathrm{C}$ for $10 \mathrm{~min}$. The sequences of forward and reverse primers for CASP8 rs3834129 were 5'-ACTCTGCATGCCAGGAGCTA-3' and 5'-CTGGGG AAGCCTCACTGTAT-3', respectively. After PCR amplification by Light Cycler (BioRad, Hercules, CA, USA), the PCR products were subject to restriction endonuclease digestion with $P v u I I$ (New England Biolabs, Beverly, MA, USA) according to the manufacturer's instructions. The digestive products were then separated using $3 \%$ agarose gel electrophoresis and visualized with ethidium bromide staining under UVC irradiation. All the genotypic processing was repeated by at least two well-trained researchers independently and blindly, and the results were $100 \%$ concordant with each other, while the success rates of PCR-restrictive fragment length polymorphism (RFLP) were $100 \%$. To confirm the results of PCR-RFLP, the genotypes of $5 \%$ of the samples chosen randomly from the overall pool (control and patient groups) were subjected to PCR direct sequencing (Genomics BioSci \& Tech Co.). The rates of concordance between direct sequencing and PCR-RFLP methods were $100 \%$ for each of the samples double-checked.

Statistical analyzing methodology. Student's $t$-test was specifically applied for the comparison of continuous variables (age) between the case and control groups. Pearson's chi-square test was applied to compare the distribution of the CASP 8 genotypes among the subgroups. The associations between CASP 8 genotypes and oral cancer risk were estimated by calculating the odds ratios (ORs) and corresponding 95\% confidence intervals (CIs) via the logistic regression analysis. Finally, any difference between the two groups at $p<0.05$ was identified as being statistically significant. 
Table II. Distributions of caspase-8 rs3834129 genotypic frequencies among the patients with oral cancer and healthy controls.

\begin{tabular}{lcccc}
\hline Genotype & Cases, n (\%) & Controls, n (\%) & Adjusted OR (95\% CI) $^{\mathrm{a}}$ & $p$-Value \\
\hline II & $453(57.5)$ & $516(54.0)$ & 1.00 (Reference) & 0.2057 \\
ID & $288(36.5)$ & $373(39.0)$ & $0.89(0.72-1.09)$ & 0.2633 \\
DD & $47(6.0)$ & $67(7.0)$ & $0.83(0.49-1.26)$ & 0.1418 \\
ID+DD & $335(42.5)$ & $440(46.0)$ & $0.86(0.69-1.14)$ & 0.3052 \\
$p_{\text {trend }}$ & & & & 0.9709 \\
$p_{\text {HWE }}$ & & & & \\
\hline
\end{tabular}

I: Insertion; D: deletion; OR: odds ratio; CI: confidence interval; HWE, Hardy-Weinberg equilibrium. aAdjusted for confounding factors: age, gender, smoking, alcohol and betel quid consumption; bBased on chi-square test without Yates' correction.

Table III. Allelic frequencies for caspase-8 rs3834129 polymorphisms among the patients with oral cancer and healthy controls.

\begin{tabular}{lcccc}
\hline Allele & Cases, $\mathrm{n}(\%)(\mathrm{n}=1,576)$ & Controls, $\mathrm{n}(\%)(\mathrm{n}=1,912)$ & ${\text { Adjusted OR }(95 \% \mathrm{CI})^{\mathrm{a}}}$ & $p$-Value \\
\hline $\mathrm{I}$ & $1,194(75.8)$ & $1,405(73.5)$ & 1.00 (Reference) & \\
$\mathrm{D}$ & $382(24.2)$ & $507(26.5)$ & $0.90(0.77-1.05)$ & 0.1244 \\
\hline
\end{tabular}

I: Insertion; D: deletion; OR: odds ratio; CI: confidence interval. aAdjusted for confounding factors: age, gender, smoking, alcohol and betel quid consumption. 'based on chi-square test without Yates' correction.

Table IV. Odds ratios for association of caspase-8 rs3834129 genotype with oral cancer after stratification by smoking habit.

\begin{tabular}{|c|c|c|c|c|c|c|c|c|c|c|}
\hline \multirow[b]{2}{*}{ Genotype } & \multicolumn{5}{|c|}{ Non-smokers, $\mathrm{n}$} & \multicolumn{5}{|c|}{ Smokers, $\mathrm{n}$} \\
\hline & Controls & Cases & OR $(95 \% \mathrm{CI})^{\mathrm{a}}$ & $\mathrm{aOR}(95 \% \mathrm{CI})^{\mathrm{b}}$ & $p$-Value ${ }^{c}$ & Controls & Cases & OR $(95 \% \mathrm{CI})^{\mathrm{a}}$ & $\mathrm{aOR}(95 \% \mathrm{CI})^{\mathrm{b}}$ & $p$-Value ${ }^{\mathrm{c}}$ \\
\hline II & 158 & 112 & 1.00 (ref) & 1.00 (ref) & & 358 & 341 & 1.00 (ref) & $1.00(\mathrm{ref})$ & \\
\hline ID & 111 & 70 & $0.89(0.61-1.31)$ & $0.93(0.75-1.24)$ & 0.5514 & 262 & 218 & $0.87(0.69-1.10)$ & $0.95(0.73-1.09)$ & 0.2553 \\
\hline DD & 20 & 11 & $0.78(0.36-1.68)$ & $0.81(0.65-1.53)$ & 0.5200 & 47 & 36 & $0.78(0.49-1.24)$ & $0.87(0.51-1.47)$ & 0.3510 \\
\hline Total & 289 & 193 & & & & 667 & 595 & & & \\
\hline$p_{\text {trend }}$ & & & & & 0.7253 & & & & & 0.4060 \\
\hline
\end{tabular}

I: Insertion; D: deletion; OR: odds ratio; aOR: adjusted OR; CI: confidence interval. ${ }^{a}$ Multivariate logistic regression analysis. ${ }^{\mathrm{b}}$ Adjusted for age, gender and alcohol drinking habit; 'Chi-square without Yates' correction or Fisher's exact test $($ when $\mathrm{n}<5)$.

\section{Results}

Comparison of basic characteristics between the oral cancer and the healthy control groups. The data ono age, gender, personal habits and primary tumor sites for the 788 patients with oral cancer and 956 non-cancer controls are summarized in Table I. Since we applied the frequency matching approach during choosing the non-cancer healthy participants, there was no difference in the frequency distribution of age and gender between the oral cancer case and control groups (Table I). Among the investigated population, it was found that betel quid chewers and smokers were significantly more frequent in the oral cancer patient group than in the control group (both $p<0.05$ ), indicating that these two lifestyle factors are potential predictors of oral cancer risk for Taiwanese (Table I). From the clinical viewpoint, tongue (41.2\%) and buccal mucosa (37.3\%) were found to be the two most common tumor sites for primary oral cancer (Table I).

Association of CASP8 genotypes and Taiwan oral cancer risk. The distributions of the CASP 8 rs3834129 genotypes among the non-cancer healthy controls and the patients with oral cancer are presented and analyzed in Table II. The genotypes of CASP8 rs3834129 were not differentially distributed among the investigated cases and the controls ( $p$ for trend $=0.3052$ ) (Table II). CASP 8 rs3834129 heterozygous and homozygous variant ID and DD genotype was not associated with altered oral cancer risk compared with the wild-type II genotype ( $p=0.2057$ and 0.2633 , respectively). In addition, in the dominant model, there was no significant 
in vivo $33: 1151-1156(2019)$

Table V. Odds ratios for caspase-8 rs3834129 genotype and oral cancer after stratification by alcohol drinking habit.

\begin{tabular}{|c|c|c|c|c|c|c|c|c|c|c|}
\hline \multirow[b]{2}{*}{ Genotype } & \multicolumn{2}{|c|}{ Non-drinkers, $\mathrm{n}$} & \multirow[t]{2}{*}{ OR $(95 \% \mathrm{CI})^{\mathrm{a}}$} & \multirow[t]{2}{*}{$\mathrm{aOR}(95 \% \mathrm{CI})^{\mathrm{b}}$} & \multirow[t]{2}{*}{$p$-Value } & \multicolumn{2}{|c|}{ Drinkers, $\mathrm{n}$} & \multirow[t]{2}{*}{ OR $(95 \% \mathrm{CI})^{\mathrm{a}}$} & \multirow[t]{2}{*}{$\mathrm{aOR}(95 \% \mathrm{CI})^{\mathrm{b}}$} & \multirow[t]{2}{*}{$p$-Value } \\
\hline & Controls & Cases & & & & Controls & Cases & & & \\
\hline II & 166 & 132 & 1.00 (ref) & 1.00 (ref) & & 350 & 321 & 1.00 (ref) & 1.00 (ref) & \\
\hline ID & 131 & 82 & $0.79(0.55-1.13)$ & $0.85(0.63-1.38)$ & 0.1903 & 242 & 206 & $0.93(0.73-1.18)$ & $0.92(0.58-1.25)$ & 0.5420 \\
\hline DD & 18 & 14 & $0.98(0.47-2.04)$ & $0.99(0.54-1.79)$ & 0.9529 & 49 & 33 & $0.73(0.46-1.17)$ & $0.85(0.52-1.13)$ & 0.1933 \\
\hline Total & 315 & 228 & & & & 641 & 560 & & & \\
\hline$p_{\text {trend }}$ & & & & & 0.4153 & & & & & 0.4038 \\
\hline
\end{tabular}

I: Insertion; D: deletion; OR: odds ratio; aOR: adjusted OR; CI: confidence interval. aMultivariate logistic regression analysis. ${ }^{b}$ Adjusted for age, gender and smoking habit. 'Chi-square without Yates' correction or Fisher's exact test (when $\mathrm{n}<5)$.

Table VI. Odds ratios for caspase-8 rs3834129 genotype and oral cancer after stratification by betel quid chewing habit.

\begin{tabular}{|c|c|c|c|c|c|c|c|c|c|c|}
\hline \multirow[b]{2}{*}{ Genotype } & \multicolumn{2}{|c|}{ Non-chewers, $\mathrm{n}$} & \multirow[t]{2}{*}{ OR $(95 \% C I)^{\mathrm{a}}$} & \multirow[t]{2}{*}{$\mathrm{aOR}(95 \% \mathrm{CI})^{\mathrm{b}}$} & \multirow[t]{2}{*}{$p$-Value ${ }^{c}$} & \multicolumn{2}{|c|}{ Chewers, $\mathrm{n}$} & \multirow[t]{2}{*}{ OR $(95 \% C I)^{\mathrm{a}}$} & \multirow[t]{2}{*}{$\mathrm{aOR}(95 \% \mathrm{CI})^{\mathrm{b}}$} & \multirow[t]{2}{*}{$p$-Value } \\
\hline & Controls & Cases & & & & Controls & Cases & & & \\
\hline II & 240 & 73 & 1.00 (ref) & 1.00 (ref) & & 276 & 380 & 1.00 (ref) & 1.00 (ref) & \\
\hline ID & 178 & 46 & $0.85(0.56-1.29)$ & $0.91(0.63-1.26)$ & 0.4432 & 195 & 242 & $0.90(0.71-1.15)$ & $0.93(0.73-1.21)$ & 0.4044 \\
\hline $\mathrm{DD}$ & 32 & 8 & $0.82(0.36-1.86)$ & $0.88(0.53-1.47)$ & 0.6379 & 35 & 39 & $0.81(0.50-1.31)$ & $0.89(0.51-1.27)$ & 0.3890 \\
\hline Total & 450 & 127 & & & & 506 & 661 & & & \\
\hline$p_{\text {trend }}$ & & & & & 0.7075 & & & & & 0.5507 \\
\hline
\end{tabular}

I: Insertion; D: deletion; OR: odds ratio; aOR: adjusted OR; CI: confidence interval. aMultivariate logistic regression analysis. ${ }^{\mathrm{b}} \mathrm{Adjusted}$ for age, gender and smoking habit. 'Chi-square without Yates' correction or Fisher's exact test (when $\mathrm{n}<5$ ).

association between CASP8 rs3834129 D-carrying genotypes and oral cancer risk compared with II wild-type genotype $(p=0.1418)$. The distribution of genotypes of CASP 8 rs3834129 in the control group fit well with the HardyWeinberg equilibrium $\left(p_{\mathrm{HWE}}=0.9709\right)$.

In order to validate the results in Table II, analysis of allelic frequency distributions for CASP8 rs3834129 was also conducted and the results are presented in Table III. Supporting the idea that genotype of CASP 8 rs3834129 was not associated with oral cancer risk, the frequency of variant allele D was $24.2 \%(n=382$ out of 1,576$)$ in the oral cancer patient group, slightly but non-significantly lower than that of $26.5 \%(n=507$ out of 1,912) in the control group ( $p=0.1244)$ (Table III).

From the epidemiological viewpoint, smoking, alcoholism and betel quid chewing habits are well-known risk factors for oral cancer in Taiwan. Therefore, we were extremely interested in evaluating the joint effects of CASP8 rs3834129 genotypes with these risky personal behaviors among the Taiwanese. Firstly, among non-smokers, those with ID and DD genotypes at CASP8 rs3834129 were at 0.89 - and 0.78 fold odds of developing oral cancer ( $p=0.5514$ and 0.5200$)$ (Table IV). After adjusting for confounding factors including age, gender alcohol drinking and betel quid chewing habit, the statistical results were still non-significant for ID and DD genotypes (Table IV). No significant effect of genotype was found among the non-smokers (Table IV). Secondly, among the subgroups of non-alcohol and alcohol drinkers, genotypes of CASP8 rs3834129 were not significantly associated with risk of having oral cancer (Table V). Among the subgroups of non-betel quid chewers and betel quid chewers CASP8 rs3834129 genotype similarly was not associated with risk of having oral cancer either (Table VI).

\section{Discussion}

The CASP8 gene encodes a cysteine-aspartic acid protease 8 which activates caspase- 3 in the apoptosis signaling cascade (30). CASP8 plays is an initiator of both extrinsic and intrinsic apoptotic pathways after being activated by Fas cell surface death receptor (FAS) and Fas-associated death domain (FADD), the Fas-interacting protein $(31,32)$. Activated CASP8 may work alone or cooperate with another apoptosis initiator caspase-10, contributing to the subsequent activation of the downstream executioner caspases, such as caspase-3 to complete the apoptotic process (33). Among the single nucleotide polymorphisms of CASP8, rs3834129 is the most commonly examined and has attracted much more interest of genomic scientists. In 2007, Sun and his colleagues firstly screened a panel of cancers to investigate the associations of CASP8 rs3834129 with each type (34), showing that the 
deletion (D) allele at CASP8 rs3834129 was associated with a reduced susceptibility to several types of cancer, such as lung, colorectal, esophageal, breast, cervical and gastric. During the period of 2008 to 2017, CASP8 rs3834129 genotype was found to contribute to personal susceptibility to melanoma (35), brain tumor (26), breast cancer (23) and kidney cancer (36). As for the contribution of $C A S P 8$ rs3834129 genotypes to oral cancer, del allele of CASP8 rs3834129 was reported to be protective in oral squamous carcinoma (37).

Mechanistically, the deletion (D) genotype at CASP8 rs3834129 was reported to destroy a stimulatory protein 1 binding element in the promoter regulatory region, reducing CASP 8 transcription and eventually reducing apoptosis of Tlymphocytes (34).

In the current study, we firstly found that the genotype of CASP8 rs3834129 was not significantly associated with oral cancer risk in a representative Taiwanese population with 788 patients with oral cancer and 956 healthy controls (Tables II and III). The highlight finding is consistent with a previous one from a study performed on a South Indian population (28) with negative association results. In addition, after adjusting for the confounding factors, there was still no association between the CASP 8 rs3834129 genotype with oral cancer risk (data not shown). Furthermore, we analyzed the interaction of CASP 8 rs3834129 genotypes and three risk lifestyle behaviors for Taiwanese, smoking, alcohol drinking, and betel quid chewing. The results indicated that there was no interaction between CASP 8 rs3834129 genotype and smoking, alcohol drinking, or betel quid chewing in determining the personal susceptibility to oral cancer (Tables IV-VI). We also examined the correlation between genotypes of CASP 8 rs3834129 and clinicopathological features of investigated patients with oral cancer in Taiwan.

In conclusion, the study provided a preliminary findings showing that CASP8 rs3834129 was not associated with altered risk for oral cancer in a Taiwanese population. Additionally, in the stratified analyses, we found no alteration of risk according to behaviors believed to contribute to the etiology of oral carcinogenesis. Moreover, the CASP8 rs3834129 variant genotype was not found to be a predictor for metastasis or recurrence.

\section{Conflicts of Interest}

All the Authors declare no conflict of interest.

\section{Authors' Contributions}

Research design: Shih LC, Tsai CW and Sun KT; patient and questionnaire summarizing: Shih LC and Shen TC; experiment performance: Hsu HM, Wang YC and Chang WS; statistical analysis: Tsai YT and Lin ML; article writing: Gong CL, Tsai CW and Bau DT; reviewing and revising: Bau DT, Chang WS and Tsai CW.

\section{Acknowledgements}

We appreciate the Tissue-Bank of China Medical University Hospital for their excellent technical assistance and all the subjects, doctors, nurses and colleagues. The perfect technology and efforts from Yu-Shih Wang and Hsin-Ting $\mathrm{Li}$ are also appreciated. This study was supported mainly by the China Medical University and Hospital (DMR-108-124) to Dr. Bau and Taiwan Ministry of Science and Technology (MOST-106-2320-B-039-035) to Dr. Bau. The special statistical double-checking by Cheng-Li Lin supported with research grant from Taiwan Ministry of Health and Welfare Clinical Trial and Research Center of Excellence (MOHW 108TDU-B-212-133004) is also highly appreciated.

\section{References}

1 Bray F, Ferlay J, Soerjomataram I, Siegel RL, Torre LA and Jemal A: Global Cancer Statistics 2018: GLOBOCAN estimates of incidence and mortality worldwide for 36 cancers in 185 countries. CA Cancer J Clin 68: 394-424, 2018. PMID: 30207593. DOI: $10.3322 /$ caac. 21492

2 Cancer Registration Report, Taiwan Ministry of Health and Welfare Clinical Trial and Research Center of Excellence. Available from: https://www.hpa.gov.tw/Pages/List.aspx? nodeid=269

3 Liang SY, Chang TT, Wu WW and Wang TJ: Caring for patients with oral cancer in Taiwan: The challenges faced by family caregivers. Eur J Cancer Care 28: e12891, 2019. PMID: 30015996. DOI: $10.1111 /$ ecc.12891

4 Tsai CW, Hsu HM, Wang YC, Chang WS, Shih LC, Sun KT, Hung YW, Yang YC, Gong CL and Bau DT: Contribution of $M M P 2$ promoter genotypes to oral cancer susceptibility, recurrence and metastasis in Taiwan. Anticancer Res 38: 68216826, 2018. PMID: 30504396. DOI: 10.21873/anticanres.13055

5 Wang F, Wang JD and Hung YW: Universal health insurance, health inequality and oral cancer in Taiwan. PLoS One 13: e0205731, 2018. PMID: 30335806. DOI: 10.1371/journal.pone. 0205731

6 Shih LC, Li CH, Sun KT, Chen LY, Hsu CL, Hung YW, Wu CN, Hsia TC, Shen TC, Chang WS, Shih TC, Tsai CW and Bau DT: Association of matrix metalloproteinase-7 genotypes to the risk of oral cancer in Taiwan. Anticancer Res 38: 2087-2092, 2018. PMID: 29599326. DOI: 10.21873/anticanres.12448

7 Sun KT, Tsai CW, Chang WS, Shih LC, Chen LY, Tsai MH, Ji HX, Hsiao CL, Liu YC, Li CY and Bau DT: The contribution of matrix metalloproteinase-1 genotype to oral cancer susceptibility in Taiwan. In Vivo 30: 439-444, 2016. PMID: 27381606.

8 Tsai CW, Chang WS, Lin KC, Shih LC, Tsai MH, Hsiao CL, Yang MD, Lin CC and Bau DT: Significant association of interleukin-10 genotypes and oral cancer susceptibility in Taiwan. Anticancer Res 34: 3731-3737, 2014. PMID: 24982395.

9 Tsai CW, Chang WS, Liu JC, Tsai MH, Lin CC and Bau DT: Contribution of DNA double-strand break repair gene XRCC3 genotypes to oral cancer susceptibility in Taiwan. Anticancer Res 34: 2951-2956, 2014. PMID: 24922659.

10 Tsai CW, Tsai MH, Tsou YA, Shih LC, Tseng HC, Chang WS, Ho CY, Lee HZ and Bau DT: The joint effect of smoking and hOGG1 genotype on oral cancer in Taiwan. Anticancer Res 32: 3799-3803, 2012. PMID: 22993322.

11 Bau DT, Tsai CW, Lin CC, Tsai RY and Tsai MH: Association of alpha B-crystallin genotypes with oral cancer susceptibility, 
survival, and recurrence in Taiwan. PLoS One 6: e16374, 2011 PMID: 21915251. DOI: 10.1371/journal.pone.0016374

12 Bau DT, Tsai MH, Tsou YA, Wang CH, Tsai CW, Sun SS, Hua $\mathrm{CH}$, Shyue SK and Tsai RY: The association of caveolin-1 genotypes with oral cancer susceptibility in Taiwan. Ann Surg Oncol 18: 1431-1438, 2011. PMID: 21246406. DOI: 10.1245/s 10434-010-1483-4

13 Bau DT, Chang CH, Tsai MH, Chiu CF, Tsou YA, Wang RF, Tsai $\mathrm{CW}$ and Tsai RY: Association between DNA repair gene ATM polymorphisms and oral cancer susceptibility. Laryngoscope 120: 2417-2422, 2010. PMID: 21108427. DOI: 10.1002/lary. 21009

14 Chen $\mathrm{M}$ and Wang $\mathrm{J}$ : Initiator caspases in apoptosis signaling pathways. Apoptosis 7: 313-319, 2002. PMID: 12101390.

15 Wang LH, Ting SC, Chen CH, Tsai CC, Lung O, Liu TC, Lee CW, Wang YY, Tsai CL and Lin YC: Polymorphisms in the apoptosis-associated genes FAS and FASL and risk of oral cancer and malignant potential of oral premalignant lesions in a Taiwanese population. J Oral Pathol Med 39: 155-161, 2010. PMID: 20359312. DOI: 10.1111/j.1600-0714.2009.00873.x

16 Kuwana T, Smith JJ, Muzio M, Dixit V, Newmeyer DD and Kornbluth S: Apoptosis induction by caspase-8 is amplified through the mitochondrial release of cytochrome c. J Biol Chem 273: 1658916594, 1998. PMID: 9632731. DOI: 10.1074/jbc.273.26.16589

$17 \mathrm{Yu}$ J, Zhang L, Hwang PM, Kinzler KW and Vogelstein B: PUMA induces the rapid apoptosis of colorectal cancer cells Mol Cell 7: 673-682, 2001. PMID: 11463391.

18 Hashemi M, Eskandari-Nasab E, Fazaeli A, Rezaei H, Mashhadi MA, Arbabi F and Taheri M: Bi-directional PCR allele-specific amplification (bi-PASA) for detection of caspase-8 $-6526 \mathrm{~N}$ ins/del promoter polymorphism (rs3834129) in breast cancer. Gene 505: 176-179, 2012. PMID: 22659694. DOI: 10.1016/ j.gene.2012.05.043

19 Du H, Song G, Fang M, Shu YQ, Zhao X and Zhu LJ: A metaanalysis of caspase- $8-6526 \mathrm{~N}$ del polymorphism and digestive tract cancer risk. J Biomed Res 33: 173-180, 2018. PMID: 30057371. DOI: $10.7555 / J B R .32 .20160030$

20 Wu Z, Li Y, Li S, Zhu L, Li G, Yu Z, Zhao X, Ge J, Cui B, Dong $\mathrm{X}$, Tian S, Hu F and Zhao Y: Association between main caspase gene polymorphisms and the susceptibility and prognosis of colorectal cancer. Med Oncol 30: 565, 2013. PMID: 23715747. DOI: $10.1007 / \mathrm{s} 12032-013-0565-0$

21 Kuhlmann JD, Bankfalvi A, Schmid KW, Callies R, Kimmig R, Wimberger P, Siffert W and Bachmann HS: Prognostic relevance of caspase $8-6526 \mathrm{~N}$ InsDel and Asp302His polymorphisms for breast cancer. BMC Cancer 16: 618, 2016. PMID: 27507139. DOI: $10.1186 / \mathrm{s} 12885-016-2662-\mathrm{x}$

22 Park HL, Ziogas A, Chang J, Desai B, Bessonova L, Garner C, Lee E, Neuhausen SL, Wang SS, Ma H, Clague J, Reynolds P, Lacey JV Jr., Bernstein L and Anton-Culver H: Novel polymorphisms in caspase- 8 are associated with breast cancer risk in the California Teachers Study. BMC Cancer 16: 14, 2016. PMID: 26758508. DOI: 10.1186/s12885-015-2036-9

23 Zhang Y, Li W, Hong Y, Wu G, He K and Liu D: A systematic analysis of the association studies between CASP8 D302H polymorphisms and breast cancer risk. J Genet 96: 283-289, 2017. PMID: 28674227.

24 Zhang CD, Li HT, Liu K, Lin ZD, Peng QL, Qin X, He M, Wu H, Mo ZN and Yang XL: Impact of caspase-8 (CASP8)-652 6N del and D302H polymorphisms on prostate cancer in different ethnic groups. Asian Pac J Cancer Prev 15: 7713-7718, 2014. PMID: 25292051.
25 Son JW, Kang HK, Chae MH, Choi JE, Park JM, Lee WK, Kim CH, Kim DS, Kam S, Kang YM and Park JY: Polymorphisms in the caspase- 8 gene and the risk of lung cancer. Cancer Genet Cytogenet 169: 121-127, 2006. PMID: 16938569. DOI: 10.1016/ j.cancergencyto.2006.04.001

26 Srivastava K, Srivastava A and Mittal B: Caspase-8 polymorphisms and risk of gallbladder cancer in a northern Indian population. Mol Carcinog 49: 684-692, 2010. PMID: 20564345. DOI: $10.1002 / \mathrm{mc} .20641$

27 Rihani A, De Wilde B, Zeka F, Laureys G, Francotte N, Tonini GP, Coco S, Versteeg R, Noguera R, Schulte JH, Eggert A, Stallings RL, Speleman F, Vandesompele J and Van Maerken T: CASP8 SNP $\mathrm{D} 302 \mathrm{H}$ (rs1045485) is associated with worse survival in MYC Namplified neuroblastoma patients. PLoS One 9: e114696, 2014. PMID: 25502557. DOI: 10.1371/journal.pone. 0114696

28 Arunkumar G, Murugan AK, Nagarajan M, Ajay C, Rajaraman $\mathrm{R}$ and Munirajan AK: Absence of the frequently reported PIK3CA, CASP8, and NOTCH1 mutations in South Indian oral cancers. Oral Dis 23: 669-673, 2017. PMID: 28181739. DOI: 10.1111/odi.12655

29 Lin KM, Yang MD, Tsai CW, Chang WS, Hsiao CL, Jeng LB, Yueh TC, Lee MC and Bau DT: The role of MTHFR genotype in colorectal cancer susceptibility in Taiwan. Anticancer Res 38: 20012006, 2018. PMID: 29599316. DOI: 10.21873/anticanres. 12438

30 Kruidering $M$ and Evan GI: Caspase- 8 in apoptosis: The beginning of "the end"? IUBMB Life 50: 85-90, 2000. PMID: 11185963. DOI: $10.1080 / 713803693$

31 Ghavami S, Hashemi M, Ande SR, Yeganeh B, Xiao W, Eshraghi M, Bus CJ, Kadkhoda K, Wiechec E, Halayko AJ and Los M: Apoptosis and cancer: Mutations within caspase genes. J Med Genet 46: 497-510, 2009. PMID: 19505876. DOI: 10.1136/jmg.2009.066944

$32 \mathrm{Li} \mathrm{J}$ and Yuan J: Caspases in apoptosis and beyond. Oncogene 27: 6194-6206, 2008. PMID: 18931687. DOI: 10.1038/ onc. 2008.297

33 Ashkenazi A: Targeting the extrinsic apoptotic pathway in cancer: lessons learned and future directions. J Clin Invest 125: 487-489, 2015. PMID: 25642709. DOI: 10.1172/JCI80420

34 Sun T, Gao Y, Tan W, Ma S, Shi Y, Yao J, Guo Y, Yang M, Zhang $X$, Zhang Q, Zeng $C$ and Lin D: A six-nucleotide insertion-deletion polymorphism in the CASP8 promoter is associated with susceptibility to multiple cancers. Nat Genet 39: 605-613, 2007. PMID: 17450141. DOI: 10.1038/ng2030

35 Li C, Zhao H, Hu Z, Liu Z, Wang LE, Gershenwald JE, Prieto VG, Lee JE, Duvic M, Grimm EA and Wei Q: Genetic variants and haplotypes of the caspase- 8 and caspase- 10 genes contribute to susceptibility to cutaneous melanoma. Hum Mutat 29: 14431451, 2008. PMID: 18563783. DOI: 10.1002/humu.20803

36 de Martino M, Haitel A, Schatzl G, Klingler HC and Klatte T: The CASP8-652 6N insertion/deletion promoter polymorphism is associated with renal cell carcinoma risk and metastasis. J Urol 190: 717-722, 2013. PMID: 23313206. DOI: 10.1016/ j.juro.2013.01.008

37 Tang YI, Liu Y, Zhao W, Yu T and Yu H: Caspase-8 polymorphisms and risk of oral squamous cell carcinoma. Exp Ther Med 10: 2267-2276, 2015. PMID: 26668627. DOI: 10.3892/etm.2015.2832

Received April 27, 2019

Revised June 6, 2019

Accepted June 7, 2019 